\title{
Argentinean Collapsibility Loess. Characterization and Evaluation on the Constrained Modulus
}

\author{
Ricardo Schiava and Gonzalo Zarazaga \\ Department of Civil Engineering, National University of Santiago del Estero, Santiago del Estero 4200, Argentina
}

\begin{abstract}
Loessic soil in the north-west of Argentina, which consists of silt and silty clay with reduced content of fine sand, has collapsible characteristics. This means that by increasing the moisture content close to the liquid limit value, the loess soil's macro porous structure breaks experiencing large volumetric deformations. The collapse pressure and soil constrained modulus are fundamentals parameters for the characterization of these soils and the study of solutions to geotechnical problems. In this work we study the loess from the north-west region of our country, especially the Santiago del Estero's plain, based on numerous field tests and laboratory tests in order to correlate the modulus and collapse pressure from double-odometer test with the blow count from SPT (standard penetration test). It also analyzes the influence of these parameters on moisture content, void ratio and the presence of salts and calcareous concretions in soils and discusses the validity of these correlations as well as those proposed by other authors.
\end{abstract}

Key words: Loess, collapsibility, constrained modulus.

\section{Introduction}

\subsection{Morph Structural Environments}

Santiago del Estero is set on the west-central region of the great Chacoparanense plain, to except of the Guasayan's saws which are at the southwest and Ambargasta and the Sumampa saws which are in the south of the province. Both of them outline the boundary between the Pampeans Saws and Chacoparanaense Basin.

Andico cycle movements impacted across the region, but during the Oligocene and Miocene part of this began to form a tectonic depression, taking the form and dimensions of its current configuration, when raising differentially the Pampean and the Sub-andean and sank simultaneously to the center of the watershed the blocks of the Chacoparanense plain. These hollowed blocks filled with the Quaternary's loessic silt sediments giving place to an accumulation plain, which gradually descended to the east and received the name of Pampean Formation [1]. The morphology of

Corresponding author: Ricardo Schiava, Dr., research fields: geomechanics, modelling and analysis of failure. the ground is determined by the type of transportation fluvial or aeolian which generated the deposit. In the last years, there has been a significant increasing in the construction of aqueducts to supply water to different locations in the region. The foundation of storage tanks and water treatment plants consist of shallow foundations or plates, which produce a pressure increase of $100 \mathrm{kPa}$ at soil contact. Settlements computed either from the constrained deformation modulus determined from oedometer tests or the Young's modulus and Poisson's ratio from empirical correlations. Collapsible soils are generally associated with an open structure formed by sharp grains, low initial density, low natural water content, low plasticity, relatively high stiffness and strength in the dry state, and often by particle size in the silt to fine sand range [2]. As their name indicates these soils can exhibit a large volume change upon wetting, with or without extra loading, thus posing significant challenges to the geotechnical profession.

Several empirical correlations have developed to estimate deformation properties of soils e.g., Schultze and Horn [3], D’Appolonia et al. [4], Cassan [5] and Bowles [6], summarize the common relationships 
between the stress-strain modulus of granular soils and the N blow count from SPT (standard penetration tests). However, any of these equations has conceived for silt loess.

\subsection{Loess Soils}

The loess are fine soils of Aeolian origin that can preserve their generated structure when they are deposited (named primary loess) or suffer alteration "in situ" or re-transportation (named secondary loess) [7]. Generally they present a macro porous structure where the grains of fine sand and silt are joined by clay bridges and salts which give them stiffness and strength. When increasing the moisture the salts are dissolved and the clays tend to expand destroying the inter particles links producing the collapse of the macrostructure of the soil [8].

\section{Loess of Santiago Plain}

The primary loess of the Santiago plain, which is treated in this paper, is made by silts (ML), clayey silts (ML-CL) and clays of low plasticity (CL) with variable content of very fine sands, of a nut-brown color and low content of moisture. In addition, there are loessic soils with characteristics of sandy silts or fine silt sands (ML, ML-SM) [9]. The analyzed samples corresponded mainly to the west region of the province and came from different geographical locations which were grouped into six types according to the percentage that pass the sieve 200 and Atterberg limits.

The physical properties of the soils: natural moisture, fraction passing sieve 200, liquid limit, plasticity index, unit weight of dry soil $\left(\mathrm{D}_{\mathrm{Ss}}\right)$, void ratio $\left(\mathrm{e}_{0}\right)$ and content of carbonate of calcium indicated in Tables 1, 2 and 3.

\subsection{Collapsibility}

Different studies based on the nature of the collapsibility emphasize the origin of the soils, the chemical composition of the particles and of the water, the presence of salts and the possibility of their dissolution by wetting. Reginatto and Ferrero [10] determined the
Table 1 Properties of soil type A and B.

\begin{tabular}{lll}
\hline Properties & \multicolumn{2}{c}{ Soil type } \\
\cline { 2 - 3 } & $\mathrm{A}$ & $\mathrm{B}$ \\
\hline Natural moisture & $6.0-12.0$ & $4.3-12.8$ \\
Passing sieve 200 & $63-75$ & $75-85$ \\
L.L. & $18.8-26.0$ & $19.1-28.2$ \\
I.P. & $4.0-6.0$ & $4.5-6.4$ \\
Dss $\left(\mathrm{kN} / \mathrm{m}^{3}\right)$ & $13.2-15.3$ & $11.9-15.1$ \\
Void ratio & $0.73-1.17$ & $0.76-1.22$ \\
$\mathrm{CO}_{3} \mathrm{Ca}$ & $1.5-3.0$ & $1.2-7.0$ \\
$\mathrm{SUCS}$ & $\mathrm{CL}-\mathrm{ML}$ & $\mathrm{CL}-\mathrm{ML}$ \\
\hline
\end{tabular}

Table 2 Properties of soil type $C$ and $D$.

\begin{tabular}{lll}
\hline Properties & \multicolumn{2}{c}{ Soil type } \\
\cline { 2 - 3 } & $\mathrm{C}$ & $\mathrm{D}$ \\
\hline Natural moisture & $3.9-10.0$ & $9.0-12.4$ \\
Passing sieve 200 & $85-92$ & $88-92$ \\
L.L. & $22.0-28.0$ & $21.7-25.0$ \\
I.P. & $4.6-6.0$ & $2.5-3.0$ \\
Dss $\left(\mathrm{kN} / \mathrm{m}^{3}\right)$ & $11.7-14.2$ & $13.2-14.3$ \\
Void ratio & $0.86-1.02$ & $0.84-1.12$ \\
$\mathrm{CO}_{3} \mathrm{Ca}$ & $1.2-3.0$ & $0.1-2.0$ \\
$\mathrm{SUCS}$ & $\mathrm{CL}-\mathrm{ML}$ & $\mathrm{ML}$ \\
\hline
\end{tabular}

Table 3 Properties of soil type $\mathrm{E}$ and $\mathrm{F}$.

\begin{tabular}{lll}
\hline Properties & \multicolumn{2}{c}{ Soil type } \\
\cline { 2 - 3 } & $\mathrm{E}$ & $\mathrm{F}$ \\
\hline Natural moisture & $6.0-15.0$ & $4.5-7.5$ \\
Passing sieve 200 & $80-98$ & $47-54$ \\
L.L. & $24.8-35.0$ & $20.8-26.5$ \\
I.P. & $7.5-10.5$ & $2.5-3.5$ \\
Dss $\left(\mathrm{kN} / \mathrm{m}^{3}\right)$ & $12.2-14.3$ & $14.3-14.9$ \\
Void ratio & $0.85-1.15$ & $0.71-0.83$ \\
$\mathrm{C}{ }_{3} \mathrm{Ca}$ & $1.3-3.5$ & $2.9-3.4$ \\
$\mathrm{SUCS}$ & $\mathrm{CL}$ & $\mathrm{ML}$ \\
\hline
\end{tabular}

influence of the fluid's property that saturates the ground in the magnitude of the collapse. Different approaches have been given for the determination of the collapse susceptibility. They could be grouped into the following:

(a) Methods based on trials for identification of soils (unit weight, Atterberg limit, granulometry, unit weight of soils);

(b) Methods based on mechanical tests, especially odometer tests;

(c) Methods based on empirical regressions for a given region. 
Among them we can first cite Denisov [11], Gibbs [12] and second Reginatto and Ferrero [10], Redolfi [13], etc.

Reginatto and Ferrero [10] showed the limitations were presented when using methods based on physical parameters in the determination of the collapsibility of the soils.

Fig. 1 shows the values of dry unit weight as a function of liquid limit in the types of loess analyzed and plotted with the boundary curves established by Denisov [11] and Gibbs [12]. Fig. 1 shows that all types of loess analyzed in this work, are collapsible soils.

\section{Compressibility}

\subsection{Compressibility Analysis}

The prediction and evaluation of the settlements on loess soils have a great relevance in the building of aqueducts, as well as other linear development works as electrical conduction lines. The settlements depend on the compressibility of the layer and infiltration and drainage conditions that must take place during the service stage. Many authors describe the deformation modulus of these soils calculated on conditions of lateral displacement null (odometer test), of the shape:

$$
\boldsymbol{E}_{s}(\boldsymbol{k P a})=\frac{\sigma^{\prime}}{\varepsilon}
$$

where $\sigma^{\prime}$ is the effective vertical stress and $\varepsilon$ the rate vertical deformation. In this study for determining the constrained modulus was adopted the reference vertical pressure $\sigma^{\prime}=100 \mathrm{kPa}$ and the corresponding vertical deformation determined in the odometer trial. Figs. 2 and 3 show the results of the double odometer trial for loessic soils of type B and type E, under conditions of natural and saturated moisture. These tests performed on undisturbed samples extracted from a hole and then they formatted in the laboratory. It can be observed the behavior of the collapse for the saturated sample with low collapse pressure in the case of soil type B. The soil type $\mathrm{E}$ shows a behavior of collapse with collapse stress and strains close to the behavior of the soil with natural moisture. In both cases there is evidence that the compressibility of the soil increases while the consolidation pressure decreases with the increment of the moisture content, however, the collapse magnitudes are different.

The difference between both samples, besides the passing sieve 200, is its voids ratio equal to 0.79 in the type $\mathrm{B}$ and 0.97 in the type $\mathrm{E}$ and their natural moistures of $3.5 \%$ and $12.6 \%$, respectively.

\subsection{Relation between Constrained Modulus and Value of SPT Test}

Francisca [14] proposed a relation between the constrained modulus of the loess obtained for a pressure of $\sigma^{\prime}=100 \mathrm{kPa}$ and the number of blows of the normalized penetration test. This correlation seems

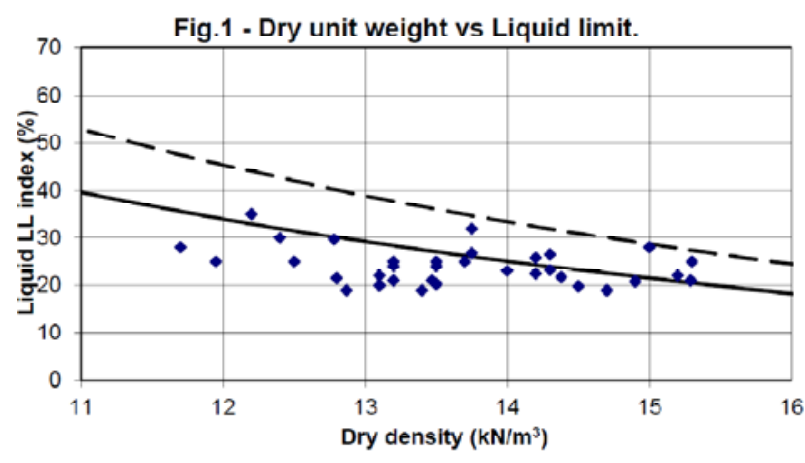

Fig. 1 Correlation between the dry unit weight and liquid limit.

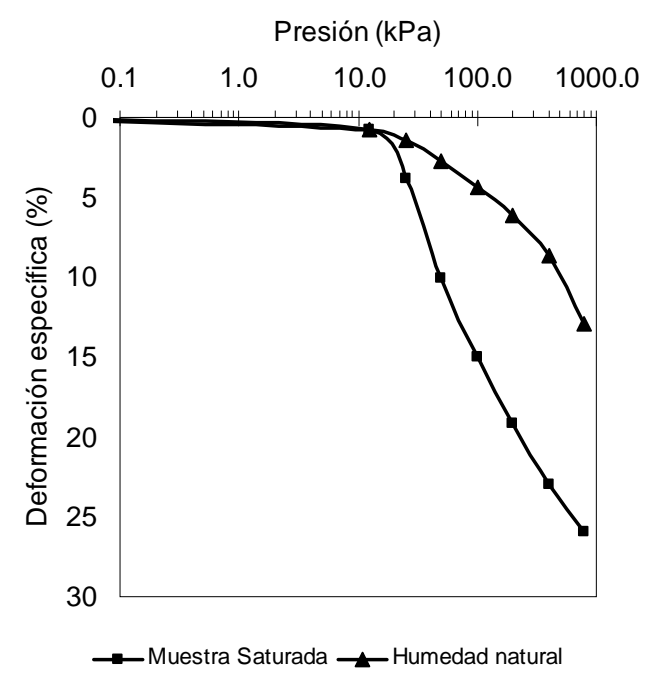

Fig. 2 Double odometer test soil type B. 


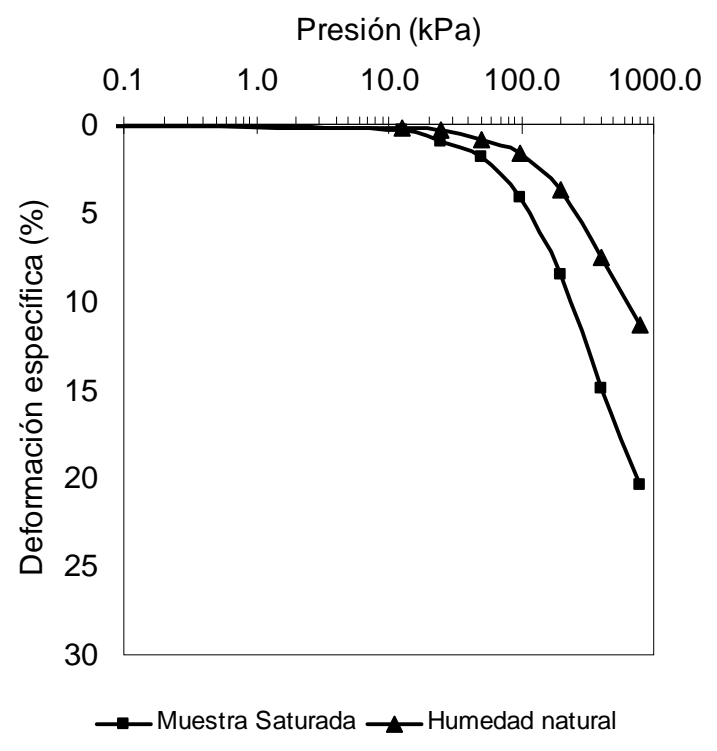

Fig. 3 Double odometer test soil type E.

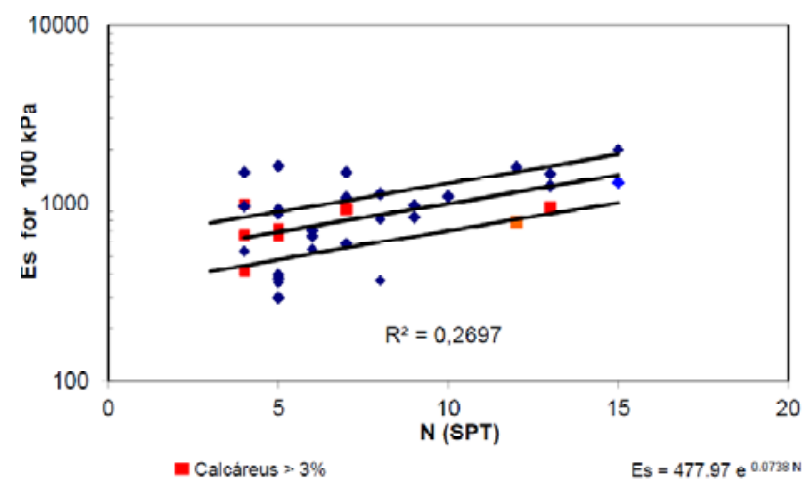

Fig. 4 Modulus Es in function of N (SPT).

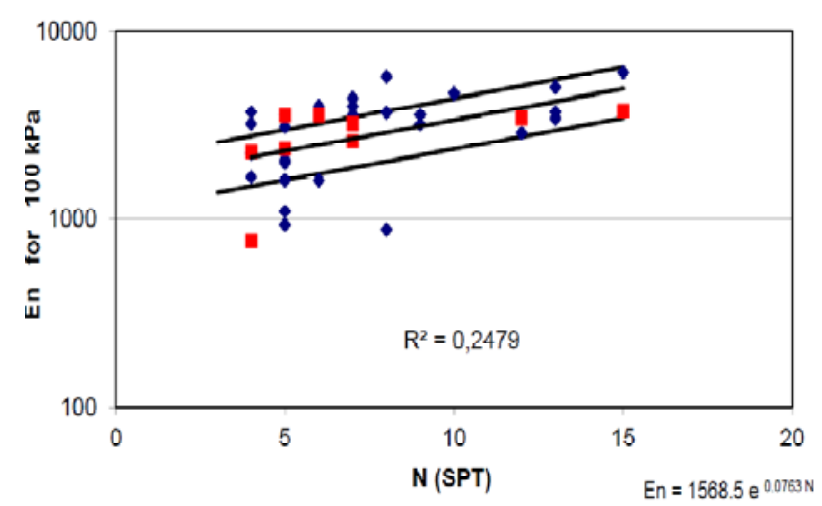

Fig. 5 Modulus En in function of N (SPT).

to be very convincing in its simplicity and because it would allow to assess settlements and the condition of collapse soil with the field data.

To investigate whether this correlation applies to study loess, Fig. 4 shows the values of the constrained modulus Es under saturated soil conditions, for a pressure of depending on the number of blows of normalized penetration type Terzaghi, N (SPT). Fig. 5 shows the modulus En, for the condition of natural moisture, for all loess samples of types A, B, C, D, E and F. It is clear that some of the studied samples contain high percentage of carbonate, although they do not appear as significant crystalline nodules or concretions. Of these, it appears that both modules increase with the increment of blows in SPT tests. However, there is a significant dispersion indicating a lack of uniformity of soil and a serious limitation on the direct application of SPT tests.

This is due to the large number of variables involved in different types of soils analyzed, such as Fraction passing sieve 200, plasticity, density of soil in natural conditions, moisture content, void ratio and salt content.

In addition, it must be highlighted that the samples of different types of loess analyzed, which may have a common or similar origin, correspond to deposits from different locations, with the peculiarities of each case.

If we select types of soil with fraction passing sieve 200 greater that $75 \%$, i.e. excluded types $\mathrm{A}$ and F, a correlation will be achieved with less dispersion as shown in Fig. 6. In this case, there is not a significant influence on this correlation of calcareous content.

The relationship between the deformation modulus in saturated conditions and an effective stress of with $\mathrm{N}$ (SPT) is expressed as:

$$
\begin{gathered}
E_{s}(k P a)=E_{s o} e^{0.074 N} \\
E_{s o}=477.97(\mathrm{kPa}) \\
E_{s o}=477.97 \pm 143(\mathrm{kPa})
\end{gathered}
$$

Variation covers 74\% of the cases of Fig. 6.

The resulting value is approximately equal to half obtained by Francisca to loess of Córdoba [14].

For the deformation modulus in natural moisture conditions, the same relation is expressed as: 


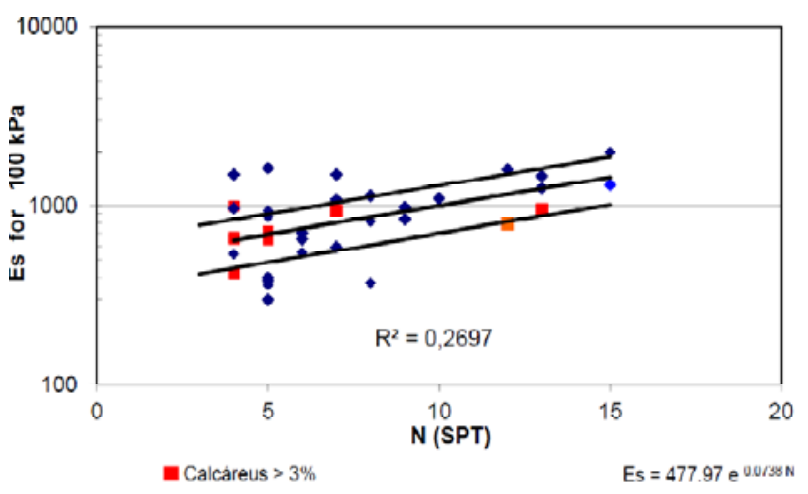

Fig. 6 Modulus Es in function of N (SPT) for soil passing sieve $200>75 \%$.

$$
\begin{aligned}
& E_{n}(k P a)=E_{n o} e^{0.076 N} \\
& E_{n o}=1568 \pm 470(k P a)
\end{aligned}
$$

In this case the variation covers only $59 \%$ of the cases indicating a greater dispersion.

\subsection{Correlation between Constrained Modulus and Void Ratio}

For all types of soil studied it is proposed a correlation between the constrained modulus Es in saturated soil conditions, for $\sigma^{\prime}=100 \mathrm{kPa}$ and the corresponding void ratio in natural state.

It is observed, that the module of soil in saturated conditions decreases with the increase of void ratio for all types of collapsible loess studied, see Fig. 7. Although it can be seen that samples with the same void ratio present very different constrained modulus, the void ratio of soil in natural conditions is one of the main variables that has influence on the deformation behavior by increasing the moisture content.

The relation obtained between Es and the void ratio $\mathrm{e}_{0}$ is expressed as:

$$
E_{s}(k P a)=E_{s}^{*} e_{0}^{-1.60}
$$

where $E_{s}^{*}=739 \pm 221(\mathrm{kPa})$ covers $55 \%$ of all types' analysed soils.

\section{Collapsibility}

Collapsibility coefficient determined in double odometer test is defined as the difference between vertical deflection experienced by the sample with natural moisture and the saturated sample, for an established vertical stress level:

$$
\delta_{\mathrm{r}}=\delta_{\mathrm{n}}-\delta_{\mathrm{s}}
$$

Different levels of collapsibility for a same stress state can be seen in the studied loess as indicated in Figs. 2 and 3.

Fig 8 shows the different magnitudes of collapsibility of the different types of soils studied based on the number of blows of the standard penetration test. It is observed that the relative collapse decreases with N (SPT), however, it can be seen a great variation in the relative collapse for a same number of blows.

The resulting relation is:

$$
\delta_{\mathrm{r}}=\delta_{0} \mathrm{e}^{-0.05 N}
$$

where $\delta_{0}=11.71$.

We can see that the reference value $\delta_{0}$ obtained, is practically the same to the one determined by Francisca [14] for loess in the province of Córdoba.

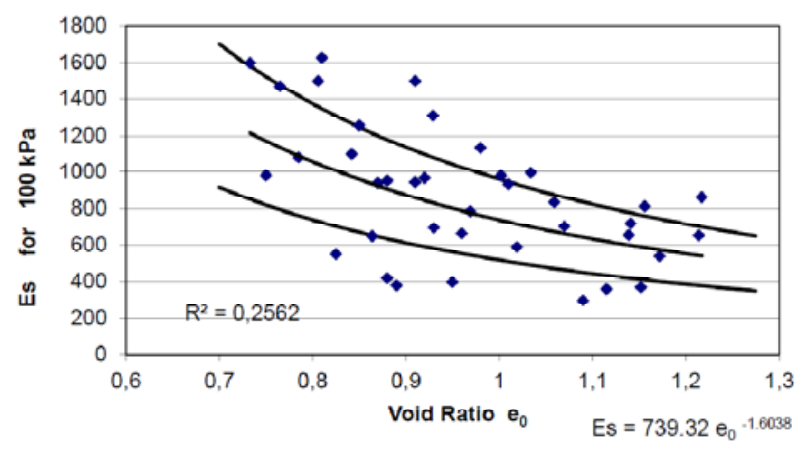

Fig. 7 Modulus Es according to void ratio.

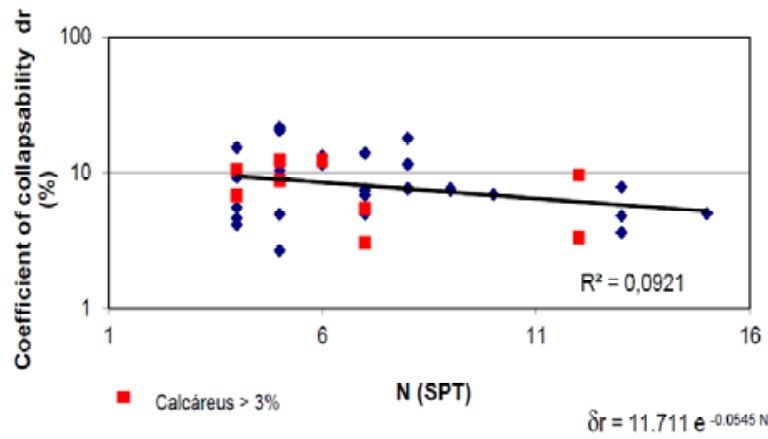

Fig. 8 Coefficient of collapsibility. 


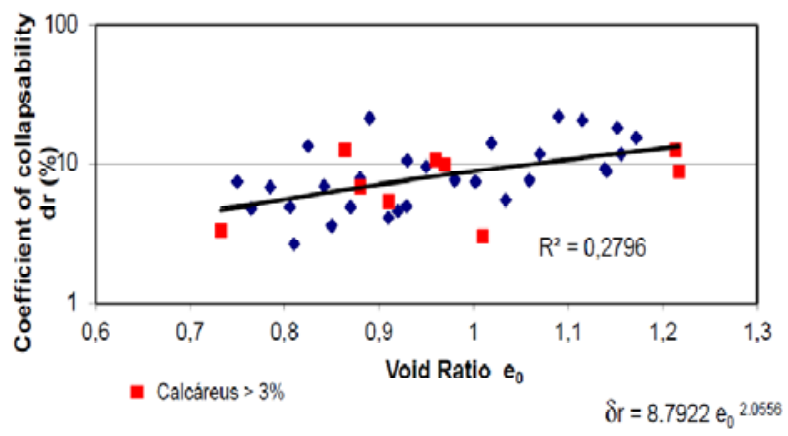

Fig. 9 Collapsibility stress and initial void ratio.

If this collapsibility coefficient is drawn according to the void ratio of soils in natural conditions, it is seen that the collapsibility increases with the growth of void ratio.

This correlation can be seen in Fig. 9, corresponding to a value of effective vertical stress of $\sigma^{\prime}=100 \mathrm{kPa}$.

This graph shows a significant variation of values of coefficient, corresponding to very different values of the coefficient of collapsibility for the same void ratio.

However, it is possible to suggest a correlation for both parameters of the form:

$$
\delta_{\mathrm{r}}=8.79 \mathrm{e}_{0}^{2.06}
$$

\section{Settlement}

The calculation of the settlement can be evaluated through the constrained modulus obtained through the proposed correlations, by the following forms.

The deformations for each layer involved can be evaluated by

$$
S=\int_{0}^{h} \frac{I_{f}}{E_{s i}} q d z
$$

where,

$q=$ contact pressure;

$I_{f}=$ coefficient witch dependent on the ratio of sides and depth of soil layer below the foundations;

$E_{s i}=$ constrained modulus obtained with the proposed relationships.

You may also evaluate through the relative collapse as:

$$
\Delta S_{c o l, i}=\sum \Delta S_{c o l, i}=\sum \delta_{c o l, i} H_{i}
$$

where, $\Delta S_{c o l, i}=$ settlement by collapse of layer $i$; $\delta_{c o l, i}=$ collapse relative layer $i$ to a state of stress $\left(\sigma_{\mathrm{i}}\right)$;

$H_{i}=$ thickness of layer $i$;

The relative magnitude of collapse $\delta_{c o l, i}$ can be estimated by Eq. (6).

\section{Conclusions}

The paper analyzes the correlation between field trials by SPT test and constrained modulus obtained in odometer tests on undisturbed loess samples.

The main conclusions are:

- The increasing the water content in the loess soil can produce the collapse of the porous macrostructure with a significant increase of volumetric strain;

- There have been proposed correlations between constrained modulus in saturated soil conditions and natural moisture, with the blows number of the SPT;

- It can be seen a substantial dispersion of values, which are reduced when the extrapolation is limited to loess with greater percentage of passing 200 sieve over $75 \%$, so that it is recommended to use only in these cases;

- The correlation between the coefficient of collapsibility of the soil and the number of blows of SPT test, allows a quick estimate of the collapse by settlement proposed;

- A relationship between the coefficient of collapsibility of the soil and the void ratio under unaltered soil condition with natural moisture is formulated;

- It is considered that the proposed correlations are valid for loess formations similar to those studied here and these are useful for the design and rapidly estimation of the settlement of shallow foundations.

\section{References}

[1] Alfredo, M. 2000. "Hydrogeology of the Province of Santiago del Estero." National University of Tucuman, Argentine.

[2] Mitchell, J. K., and Soga, K. 2005. Fundamentals of Soil Behavio. Hoboken, N.J.: John Wiley \& Sons.

[3] Schultze, E., and Horn, A. 1967. "Base Friction for Horizontally Loaded Footings in Sand and Gravel." Geotechnique 17 (4): 329-47.

[4] D’Appolonia, D. J., D'Appolonia, E. D., and Brissette, R. 
F. 1968. "Settlement of Spread Footings on Sand." Journal of Soils Mechanics and Foundation Division, ASCE 94

[5] Cassan, M. 1982. "Les Essais in situ en Mecanique des Sols.” Associate Technical Editors, Barcelona.

[6] Bowles, J. E. 1988. Foundation Analysis and Design. New York: McGraw-Hill.

[7] Rocca, R. J., Redolfi, E. R., and Terzariol, R. E. 2006. "Geotechnical Characteristics of Argentinean Loess." International Journal of Natural Disasters, Accidents and Civil Infrastructures VI (2): 149-66.

[8] Rocca, R. J. 1985. "Review of Engineering Properties of loess.” Rep. No. CE 299, Univ. of California, Berkeley.

[9] Schiava, R., and Lucio, T. E. 1996. "Collapsible Soils of Santiago del Estero.” Engineering Council of Santiago del Estero.
[10] Reginatto, A. R., and Ferrero, J. C. 1973. "Collapse Potential of Soils and Soil Water Chemistry." 8th Int. Conf. on Soil Mechanics and Foundation Engineering (ISSMFE) 2: 177-83.

[11] Denissov, M. 1961. "Oral Discussions Section Technique 7." 5th Int. Conf. on Soil Mechanics and Foundation Engineering 3: 374-5.

[12] Gibbs, H., and Bara, J. 1967. "Predicting Problems of Collapsing Soil." Journal of Soil Mechanics and Foundation Div. ASCE 93: 577-94.

[13] Redolfi, E. 1980. "Rapid Determination of the Yield Pressure in Loess Soils." VI RAMSIF, Argentina.

[14] Francisca, F. M. 2007. "Evaluating the Constrained Modulus and Collapsibility of Loess from Standard Penetration Test." Int. Journal of Geomechanics (ASCE) 7: 307-10. 